\title{
La figura histórica en los murales de escuelas primarias de la ciudad de Chihuahua
}

\author{
The historical figure in elementary schools murals in \\ the city of Chihuahua
}

\author{
Adán Erubiel Liddiard Cárdenas* \\ Guillermo Hernández Orozco***
}

\begin{abstract}
*Estudiante del Doctorado en Educación, Artes y Humanidades de la Universidad Autónoma de Chihuahua (México), el cual pertenece al Programa Nacional de Posgrados de Calidad (PNPC) del Consejo Nacional de Ciencia y Tecnología (Conacyt). Es Licenciado en Diseño Gráfico y Maestro en Docencia. Publicó el artículo "El otro muralismo en la ciudad de Chihuahua" (2019) en RECIE. Revista Cientifica de Investigación Educativa, vol. 4, núm. 2. Entre sus temas de interés está la historia del arte. Correo electrónico eliddiard@hotmail.com

http://orcid.org/0000-0002-6572-024X

**Profesor de la Universidad Autónoma de Chihuahua (México). Es doctor en Ciencias de la Educación por el Instituto Superior Pedagógico Enrique José E. Varona (Cuba). Entre sus publicaciones recientes están: "José Joaquin Calvo López, fundador del Instituto Científico y Literario, hoy Universidad Autónoma de Chihuahua" en IE Revista de Investigación Educativa, Vol. 8, No. 14, (2017) e Historia a Debate (Cinco Tomos). Obtuvo el reconocimiento Eduardo Flores Kastanis a la Investigación Educativa 2018. Cuenta con reconocimientos al Perfil Prodep y del Sistema Nacional de Investigadores, nivel 1. Sus temas de interés son la historia e historiografia de la educación.Correo electrónico ghernand@uach.mx
\end{abstract}

http://orcid.org/0000-0001-7287-8240

Historial editorial

Recibido: 15-enero-219

Aceptado: 06-marzo-2109

Publicado: 29-abril-2019 
La figura histórica en los murales de escuelas primarias de la ciudad de Chihuahua

\section{Resumen}

La institución educativa suele tener una imagen sobria en su fachada, decorada únicamente con los colores oficiales. En este contexto, son pocos los establecimientos en los que se crean murales escolares, brindando vida y color al ambiente, pero también identidad a las personas que ahí estudian o laboran. El presente trabajo documenta y analiza las obras murales con figuras históricas encontradas en las escuelas primarias de la ciudad de Chihuahua, abriendo la reflexión hacia la importancia que este tipo de mural cobra dentro del plantel, el status institucional que puede llegar a tener, su carácter educativo hacia el alumnado y la relación que guarda con la historia del arte y la escuela del Muralismo Mexicano. Igualmente ofrece una breve interpretación de los distintos elementos a resaltar en las obras expuestas.

Palabras clave: Murales, escuela primaria, historia, identidad. 
The historical figure in elementary schools murals in the city of Chihuahua

\begin{abstract}
Educational institutions tend to have sober, simple facades, using only their official colors. Nevertheless, school murals are painted to create a more cheerful and lively atmosphere and to give a sense of identity to the people who study and work there. This article reports on and analyzes the mural works with historical figures of the elementary schools in Chihuahua city, and reflects on their importance within the institution, the possible status they may have, their educational attributes to the students, and their relationship to art history and Mexican Muralism. In addition, it presents a brief interpretation of the most important elements of the different murals presented here.
\end{abstract}

Keywords: Murals, elementary school, history, identity. 
La figure historique dans les peintures murales des écoles primaires de la ville de Chihuahua

\section{Résumé}

L'institution d'enseignement a généralement une image sobre de sa façade, décorée uniquement avec ses couleurs officielles. Dans ce contexte dépouillé, les peintures murales de l'école sont créées, donnant vie et couleurs à l'environnement, mais aussi identité aux personnes qui y étudient ou y travaillent. La présente étude documente et analyse les œuvres murales avec des personnages historiques découverts dans les écoles primaires de la ville de Chihuahua, en ouvrant la réflexion sur l'importance que ce type de peinture murale occupe sur le campus, le statut institutionnel qui peut en résulter, le caractère éducatif qu'il génère envers les étudiants, et la relation qu'il entretient avec la branche historiciste de l'art et l'école du muralisme mexicain. Il propose également une brève interprétation des différents éléments à mettre en valeur dans les œuvres exposées.

Mots-clés: Peinture murale, école primaire, histoire, éducation, identité. 


\section{Introducción}

El presente artículo es producto parcial de una investigación doctoral que lleva por nombre Muralismo en la ciudad de Chihuahua: Historia local a través de la iconografía, entendiendo esta última como la interpretación de las obra de arte por medio de los símbolos o atributos de los personajes presentados. Dicha investigación tiene como eje central el rescate de los murales en la ciudad de Chihuahua, la categorización de estos en distintos grupos temáticos, y la interpretación final con fundamentos semióticos e iconográficos para encontrar una continuidad e interacción con la identidad social de la comunidad. A pesar de existir publicaciones sobre este objeto de estudio, son trabajos que tratan de una obra o de un conjunto de obras, o se centran en un autor en particular. La investigación en curso se abre integral, intentando albergar la mayor cantidad de propuestas muralistas posibles.

Este documento se centra en los murales de escuelas primarias, dentro de uno de los mencionados grupos temáticos, el referente a las instituciones educativas. Metodológicamente, la localización de estas obras se hizo de forma aleatoria y por recomendaciones del mismo personal con el que se tuvo contacto en las escuelas, a manera de bola de nieve. Este personal, administrativos, docentes o directivos, relataron y describieron de manera oral el proceso de elaboración de los murales, así como quienes participaron en esto. Los comentarios obtenidos resultaron de valía para el análisis subsecuente.

Se han visitado once escuelas primarias hasta el momento, de las cuales cuatro tienen dentro de sus instalaciones por lo menos un mural con una representación clara y protagónica de una figura histórica mexicana. Se procedió a su rescate fotográfico, el cual se presenta aquí, 
ya que la naturaleza visual del tema se extiende a este artículo, especificando al pie de cada mural su autor o autores correspondientes.

También se expone una interpretación asociativa entre las características de los paradigmas históricos presentados por Santana (2005), y las particularidades de simbología, ideas y contenido que se pueden encontrar en los murales, en este caso de las escuelas primarias. Con esto se proyecta obtener herramientas para un análisis integral, en relación a la temática del personaje histórico.

El objetivo del presente artículo es generar una reflexión válida del por qué del uso del personaje histórico en los murales encontrados en las escuelas primarias de la ciudad, ayudando de paso a dar forma al análisis de resultados actuales, en la referida investigación doctoral que fundamenta este documento.

\section{El mural en las escuelas primarias}

El muralismo es una manifestación artística plástica que nace desde los albores de la humanidad, en el Paleolítico, por la necesidad de plasmar acontecimientos o situaciones relevantes en los muros de los sitios en donde habitaban o se trasladaban las personas de una comunidad. Así, se convirtieron en un documento abierto para conocer qué había ocurrido ahí, y el contexto que rodeaba el suceso presentado. Esto perduró a través de la historia, con cada civilización adoptando su

128 cosmología de la vida y técnicas pictóricas propias.

Los murales guardan siempre un carácter público, y esto significa que quedan expuestos a las inclemencias del clima y a la manipulación y vandalismo de terceros. Por ello el muralismo, más que cualquier otra expresión pictórica, es efímero y dependiente del ambiente que lo 
rodea. Con esta particularidad se enfrenta no sólo el historiador de arte, sino el historiador en general, buscando en estos documentos abiertos y efímeros respuestas a incógnitas que surgen por otros medios, ya sean escritos $u$ orales. Con esta consigna es que se voltea hacia estos elementos artísticos, que pudieran parecer meramente decorativos o creados para resaltar la arquitectura de un edificio. Por esto se necesitan apreciar los elementos detrás de sus meros trazos. Gombrich (2003) menciona que el estudio de murales necesita "el tipo de pregunta que el historiador debería formular al enfrentarse a los monumentos del pasado. Hay que reconocer que es probable que ninguna acción ni creación humana sirva únicamente a un fin" (p. I4).

Teniendo lo anterior en mente es que se da el encuentro con las obras murales de la ciudad de Chihuahua para la investigación doctoral mencionada, teniendo la sapiencia de que los trazos y los colores en ellos dicen algo más que lo meramente decorativo. El caso particular de los murales de las escuelas primarias no es la excepción.

El recurso de usar elementos simbólicos en el arte llega desde su inicio, como actividad humana inherente. En el muralismo, va desde las representaciones de animales en las cavernas figurando la buena temporada de cacería que se había tenido o el valor del líder del clan por haber capturado más presas, y llega hasta la imaginería alegórica que José Clemente Orozco, Diego Rivera y David Alfaro Siqueiros utilizaron para dar forma visual a la reconstrucción del México postrevolucionario.

En definición de Jung (1995), "una palabra o una imagen son simbólicas cuando representan algo más que su significado inmediato y obvio" ( $p$. 20). En el muralismo, este dualismo de ideas es aprovechado sobre todo en los frescos renacentistas, debido la carga religiosa y mística de la época. Aunque el simbolismo no es asignatura privativa del arte, este 
abre la puerta al muralista a incluir detalles que muevan la asociación de ideas, no sólo en relación a la religión o espiritualidad, sino con respecto al momento histórico y la situación social en la que se creó la obra. Esto destaca en los trabajos de la mencionada trinidad del Muralismo Mexicano, Orozco, Rivera y Alfaro Siqueiros, que aunque no fueron los únicos en su época, sí son los más reconocidos hasta hoy.

De los murales de la postrevolución en México se pueden diseccionar varios símbolos generadores de múltiples significaciones, que aunque forjados de la visión de los creadores en un principio, generalmente se extienden a las interpretaciones actuales. Estos símbolos, parte de la memoria colectiva, fueron auxiliares en la formación de una cultura visual hacia un discurso de nación e identidad mexicana moderna (Sierra, 20I6).

Aunque es importante señalar que los símbolos no son un elemento definido, ni que la interpretación es única. Jung (1995) también menciona que el valor del símbolo va ligado a aspectos inconscientes en el espectador, que es difícil explicarlo o definirlo, y que supera la razón. Se puede entonces concluir que el símbolo apela a conocimientos más allá de lo cotidiano, a información que queda grabada en la psique a través de toda una vida. Más aún para las personas en este final e inicio de siglo, donde los símbolos se aprecian diariamente en el bombardeo visual de los medios de comunicación y la publicidad.

Regresando al Muralismo Mexicano, es antecedente directo al tipo de

130 mural escolar que se interesa analizar. En los recorridos y visitas a las escuelas primarias en Chihuahua capital se encontraron distintas manifestaciones murales. Los primeros se ubican por afuera de las instalaciones, casi siempre en la barda perimetral. Son murales urbanos y grafiti, realizados generalmente por grupos juveniles marginados, o colectivos de artistas callejeros en busca de espacios de expresión. En el 
interior, con permiso de las autoridades escolares y siendo tarea directa asignada por un docente, se pueden observar los segundos, murales hechos por los mismos alumnos. Estos se aprecian alegres y coloridos, con la visión inocente de los niños de primaria, aunque sin demeritar el mensaje social que muchos plasman en sus trazos.

Pero no es sino el tercer tipo de mural, el que se expone en el presente artículo, en donde se encuentra un carácter más formal, más institucional. Es el que se presenta como el rostro que da la escuela a su personal, alumnado y visitantes, y que se pinta en su muro principal. Por lo general puede ser observado desde casi cualquier rincón de la institución, se presenta inmediatamente al entrar por el portón de entrada, o está a una altura y ángulo particular que puede ser apreciado desde la calle.

Es también común que esté directamente enfrente del patio principal, donde se llevan a cabo los honores a la bandera, los actos cívicos, las graduaciones y las kermeses escolares. Por esta razón suele ser utilizado de fondo para fotografías en donde las autoridades quieren resaltar la participación de la primaria, y el honor que esto genera en su comunidad escolar.

Para la investigación se acotó aún más, considerando sólo a los que presentan figuras históricas como leitmotiv de la estructura visual y temática, dejando de lado los que manejan distintas imágenes, como las escenas infantiles y las palabras representativas de valores universales. Así, por ejemplo, está el encontrado en la Escuela Primaria Guadalupe Victoria No 253I, ubicada en la calle 32a \#I825, de la colonia Santa Rita (ver imagen $\mathrm{I}$ ). 


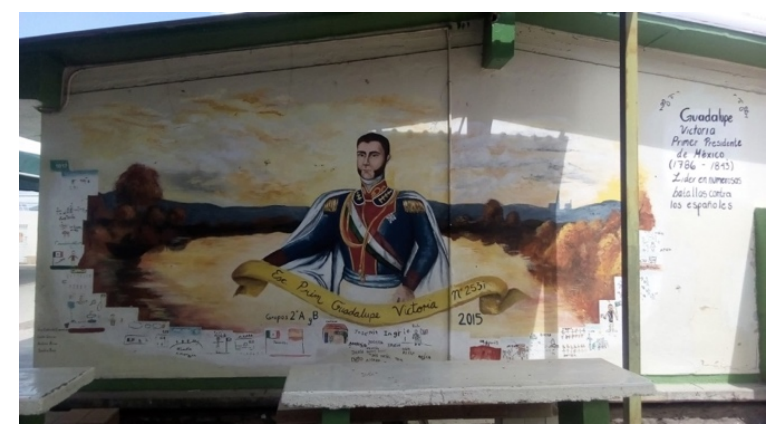

Imagen I. Mural I. Guadalupe Victoria. Autoras: Esparza, García, Perea y Ruiz. Fotografía: Adán Erubiel Liddiard.

En este primer acercamiento al mural con figura histórica se pueden encontrar algunas características mencionadas anteriormente, como que se sitúa justo detrás del portón de reja de entrada, pudiendo ser visto desde el exterior y siendo el primer referente visual al ingresar a la escuela. En él se representa al primer presidente del México independiente, Guadalupe Victoria, en actitud solemne pero serena, sin rasgos beligerantes ni impulsivos (ver imagen 2). Contiene la tranquilidad que pudiera desearse del primer gobernante de una nueva nación. Sin embargo ostenta una mirada fija y decidida, observante de la llegada de los niños por el portón de entrada cada mañana desde 20I5, cuando fue pintado.

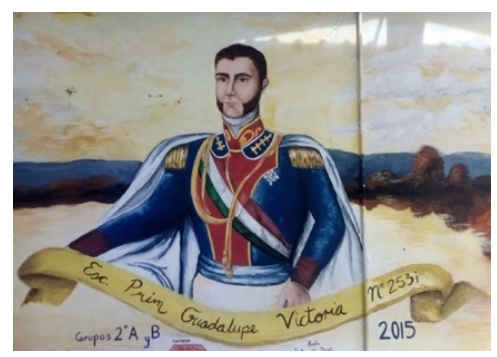

Debates por la Historia -Artículos 
Imagen 2. Mural I. Detalle de la figura histórica. Fotografía: Adán Erubiel Liddiard.

El paisaje detrás del personaje es un atardecer, con matices asociados a la serenidad, y creando un marco en tonalidades amarillas junto al suelo agreste de la campiña, resaltando la figura central. El vestuario militar de gala tiene concordancia cromática con la cordillera detrás y con el horizonte, resultando en conjunto una composición agradable y muy clásica del personaje resaltado dentro de su entorno histórico. El conjunto se asemeja a las estampas escolares que los alumnos de primaria utilizan para sus tareas de historia.

Esta última particularidad hace del mural una obra accesible para el niño, algo cercano a lo que visualiza constantemente con referencia a los personajes históricos que estudia. Para esto es necesario que el artista se alejé de cualquier interpretación o sesgo que tenga al respecto de la figura histórica y su legado, y que la estética que maneje corresponda a la representación clásica tomada de otros medios, como fotografías o pinturas creadas con anterioridad. Aunque el requerimiento de hacer el mural con estas características, como cualquier otro, se debe de plantear desde un principio por las autoridades que lo solicitan.

Al respecto de esto, al visitar la escuela Guadalupe Victoria, personal que estaba presente en ese momento proporcionó información sobre las autoras del mural, indicando que fueron un grupo de practicantes de la Facultad de Artes de la Universidad Autónoma de Chihuahua, pero no teniendo disponible el dato de sus nombres. Sin embargo estos se aprecian en la firma del mural, en la parte inferior izquierda (ver imagen 3). 


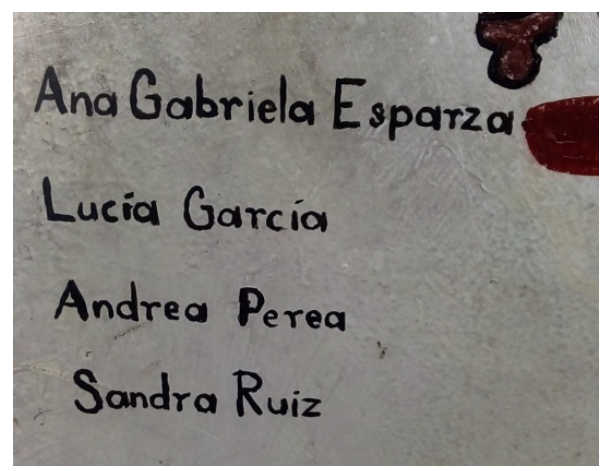

Imagen 3. Mural I. Detalle de la firma de las autoras. Fotografía: Adán Erubiel Liddiard.

El segundo tipo de mural escolar mencionado, el creado por los alumnos, busca alentar la creatividad de estos y el manejo de las técnicas aprendidas en la materia de artísticas. En la obra de Guadalupe Victoria se presenta también esta variante, en la parte izquierda e inferior, en donde los alumnos de 2 do grado pintaron una serie de escenas bélicas referentes a la Independencia de México con su propio estilo y capacidades. Esta mezcla de mural institucional creado por artistas, y mural escolar creado por alumnos, es encontrado únicamente en esta escuela, Guadalupe Victoria, siendo un híbrido a tomar en cuenta por la peculiaridad, probablemente sugerida por las mismas practicantes (ver imagen 4 ). 


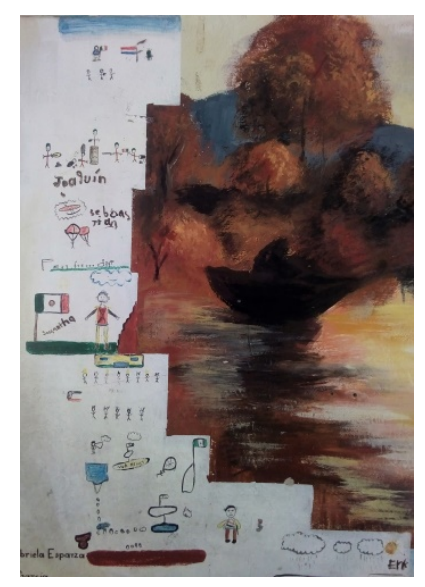

Imagen 4. Mural i. Detalle de las pinturas anexas de los alumnos. Fotografía: Adán Erubiel Liddiard.

Como se observa en esta primera aproximación al muralismo institucional a nivel primaria, el valor de la figura histórica como tal ofrece elementos de solemnidad que algunos planteles educativos buscan como valores a transmitir. Como ejemplo se aprecia el texto dedicado a Guadalupe Victoria con el que las autoras rematan su obra, y donde apuntalan la etiqueta que lleva una obra de estas características (ver imagen 5). 


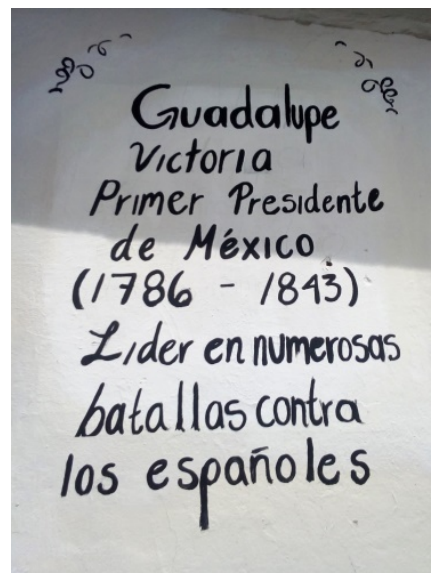

Imagen 5. Mural I. Detalle del texto informativo. Fotografía: Adán Erubiel Liddiard.

\section{Uso de la figura histórica}

La particularidad de las obras murales con figuras históricas como eje central temático y visual, consiste en que para entender por qué y en qué ocasiones se presenta esto en las obras artísticas, se necesita retroceder en la historia de la humanidad. La respuesta puede iniciarse desde la antigua Grecia, con la exaltación que presentaban sus artistas y filósofos a la esencia antropomórfica, glorificando la figura de los héroes homéricos como portadores de los valores que culminan el ideal humano (Read, I954).

La representación de la persona que tiene atributos mayores al del simple ciudadano común y corriente continuará a lo largo de la historia, específicamente en la Roma Imperial. Ahí se edificaría una exaltación hacia los líderes militares a lo largo y ancho de los territorios conquistados, en Europa, Asia y África. Esta práctica simbólica se 
entendió entonces como una efectiva muestra de poderío político y militar.

En la Edad Media la religiosidad abrumante dio pie a que las figuras históricas se remplazaran por ángeles, vírgenes, santos y cristos de mirada perdida y cuerpos lacerados. La idealización del líder conquistador de antaño cambio por seres celestiales y personas viviendo en gracia. De nuevo, estas formas, ahora en los cotizados frescos de los maestros pintores de la época, eran portadoras de los valores que culminaban el ideal humano del Medioevo.

Ya en el Renacimiento se redescubre el humanismo de la Época Clásica, y se vuelve a la exaltación del cuerpo humano por encima del sufrimiento (Read, 1954). Junto a las representaciones religiosas, todavía muy solicitadas por el gigantesco mecenas que seguía siendo la Iglesia Católica, empezaron a colarse héroes antiguos a pinturas y demás obras plásticas, sobre todo al acercarse el Neoclasicismo. La justificación fue la nostalgia que provocaban en las clases letradas, y porque se empezaba a apreciar de nuevo los valores humanos, no celestiales, que envestían a los grandes personajes.

Es Santana (2005), quien en su estudio de los paradigmas que dan forma a la práctica historiográfica, reflexiona sobre el uso de la figura histórica ya en la Edad Contemporánea. Menciona al paradigma historicista, con Leopold Von Ranke a la vanguardia, como el iniciador de una nueva manera de documentar la historia en las primeras décadas del siglo XIX. En este periodo, los renombrados estadistas modernos empiezan a tener una abrumadora exposición.

Es de tomar en cuenta que este Historicismo se desarrolla en el contexto del Romanticismo europeo, por lo que el pensamiento de la época parece impregnar con su nostálgica glorificación del pasado, el trabajo 
de aquellos historiadores, todo en plena ebullición de la Revolución Industrial. Los cronistas apuntalaron esfuerzos en pos de hacer públicas la vida y obra de los personajes icónicos (Santana, 2005). Y los artistas no tardaron en hacerse partícipe de la novedad, basta recordar el pasaje de sublimación que tuvo Ludwig Van Beethoven con Napoleón Bonaparte, al reconocerlo como la personificación de los ideales de la Revolución Francesa, llegando al grado de dedicarle su Sinfonía No. 3, Heroica.

Pero volviendo al Historicismo, este romanticismo enaltecido hacia los estadistas, militares y políticos, al ser trasladado a la población fue creando identidad, es decir un orgullo hacia los personajes propios de cada región. Esto, aunado al deseo de crear territorios fuertes y estables, los países como se conocen hoy en día, dio pie a la formación de los nacionalismos. El Estado tomó el papel de personaje, al ser ya visto por sus ciudadanos como un ente apersonado y cercano a ellos, no como un pensamiento abstracto (Santana, 2005).

Al contrario de lo anterior, los héroes se transformaron en brújula moral para la población del país de procedencia y sus vidas se transmitieron por medio de la educación del Estado hacia los niños, en un modo de adoctrinamiento y culto a la personalidad. No es difícil percatarse que esta manera de asegurar el nacionalismo en los ciudadanos ha persistido durante siglos, hasta nuestros días. En medio de esto, el muralismo adoptó este papel, a veces adoctrinador, a veces meramente educativo, aunque la línea entre ambas acciones es difusa.

El mural presentado a continuación, como los demás en este trabajo, tiene elementos para ser considerado dentro del terreno del Historicismo, tanto como práctica de difusión histórica, como elemento de identidad nacional. Es el encontrado en la Escuela Primaria Federal 
Josefa Ortiz de Domínguez, ubicada en la calle Emiliano Zapata s/n, de la colonia Villa Juárez (ver imagen 6).

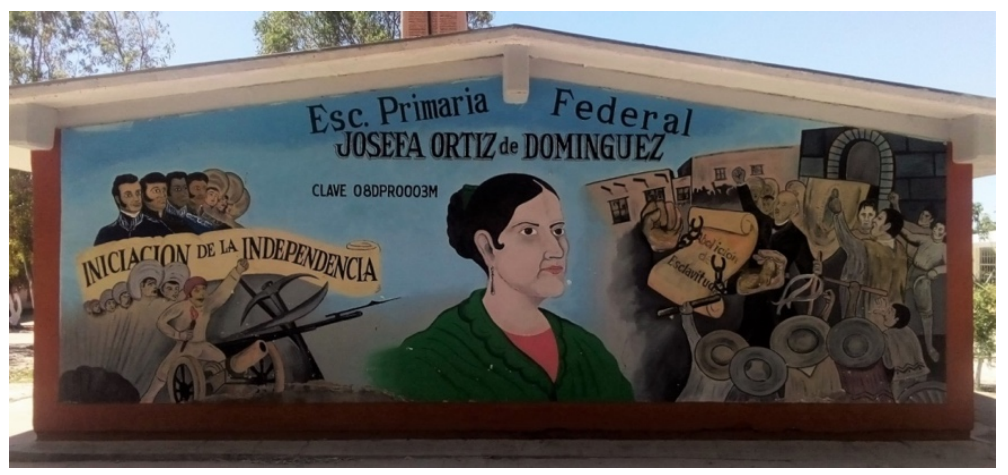

Imagen 6. Mural 2. Josefa Ortiz de Domínguez. Autor: Desconocido. Fotografía: Adán Erubiel Liddiard.

En este se puede apreciar en un plano central y muy destacado el busto del personaje principal, Josefa Ortiz de Domínguez, pieza clave en las reuniones secretas de conspiración para la Independencia de México del Reino de España. Se vuelve a detectar que el personaje elegido para protagonizar el mural es quien le da nombre a la escuela, en un franco patrón de relación directa en este sentido.

El semblante de la figura histórica, al igual que el anterior analizado en el mural de Guadalupe Victoria, se nota sereno, apacible, pero lleno de determinación. Si bien puede parecer que tiene ciertos rasgos de disgusto, posiblemente representando la situación de hartazgo social que se empezaba a generalizar en ciertos círculos poblacionales de la entonces Nueva España. Su vestuario es sencillo, nada suntuoso; inclusive el tocado de su cabello recogido refleja esto. Pero es de subrayar que los colores elegidos para este vestuario y tocado son los de la bandera mexicana, esto en combinación con lo pálido de su piel (ver 
imagen 7). Se crea así un notorio paralelismo entre la persona y el concepto de nación, apelando incluso a lo subliminal.

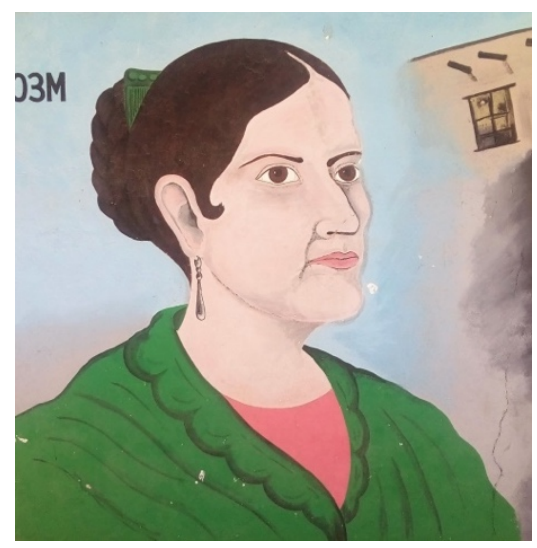

Imagen 7. Mural 2. Detalle de la figura histórica. Fotografía: Adán Erubiel Liddiard.

En esta pintura ya se aprecian elementos extras, como un par de estampas simbólicas que la flanquean, una de cada lado, dando un equilibrio en la configuración visual general. Estas pequeñas escenas refuerzan la temática de la Independencia, inherente en la trayectoria del personaje central. Esta forma narrativa, en el contexto particular observado, es sutilmente parecida a la que manejó Diego Rivera en su mural Epopeya del pueblo mexicano, situado en los muros de la escalera principal del Palacio Nacional de México, por ejemplificar sólo una obra de este tipo.

140 Es una forma de contar una historia lineal a base de escenas conclusivas perfectamente reconocibles, pero que en la composición global se entrelazan por los detalles que desprenden sus mismos personajes $u$ objetos. Es una narrativa pictórica bastante usada en murales de carácter histórico e integral, en donde se realzan los puntos más populares y dramáticos de la historia de un pueblo o país. En México, 
Rivera, junto a los demás artistas de la época, desarrollaron magistralmente esta forma de relatar el pasado.

Este tipo de mural historicista también se encuentra en Chihuahua capital, principalmente en el trabajo de Aarón Piña Mora en los murales que engalanan el Palacio de Gobierno. También en la obra de Leandro Carreón remarcada en sus murales del Paraninfo de la Rectoría de la Universidad Autónoma de Chihuahua. Y aunque ambos conjuntos murales son los más reconocidos en la comunidad, el presente trabajo ofrece ya escarceos de que la visión artística historicista se aprecia ahora continuada en las paredes de las escuelas primarias.

Continuando con las escenas complementarias en el mural de Josefa Ortiz de Domínguez, la primera de izquierda a derecha presenta la frase Iniciación de la Independencia, en franca alusión al periodo histórico en que Ortiz de Domínguez tuvo participación. Se acompaña en la parte superior de los bustos de los líderes militares Ignacio Allende, Mariano Abasolo, Juan Aldama, entre otros; quienes comenzaron esta gesta armada. Son representaciones más pequeñas en tamaño que la central de la protagonista, y se presentan a manera de fila organizada, todos con la mirada puesta al frente, hacia la esperada culminación de la victoria.

En la parte inferior se muestra la base del movimiento armado, en quien realmente se soportan los héroes de guerra: el pueblo inconforme. La figura principal lleva una antorcha en una mano, y la otra con el puño levantado, ambos elementos de la lucha armada popular. Este personaje anónimo está seguido por múltiples compañeros que se transforman en una sola masa amorfa, sin individualidades, tal y como un ejército lo es. A un lado se confunden las armas y las herramientas de trabajo, apiladas para ser usadas en el combate (ver imagen 8). 


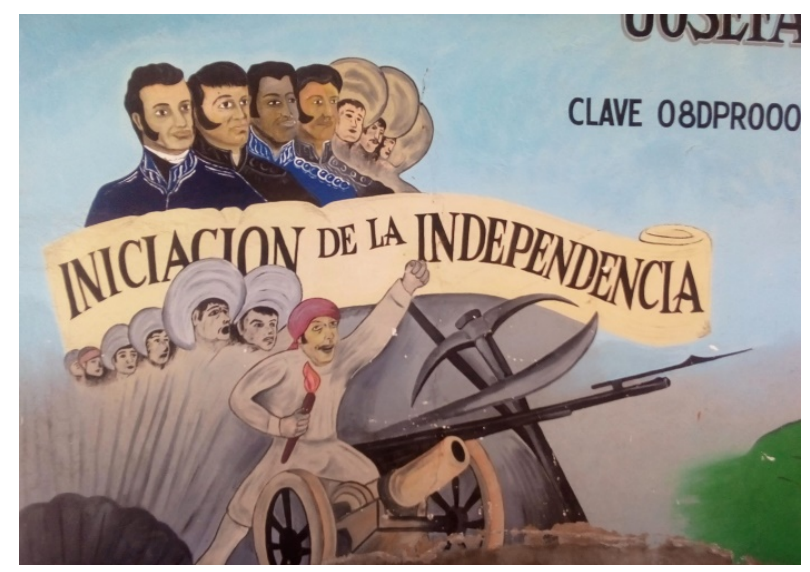

Imagen 8. Mural 2. Detalle de la escena I. Fotografía: Adán Erubiel Liddiard.

En el lado derecho, la segunda escena es más reconocida, siendo la tradicional representación del Grito de Dolores, imagen insigne del movimiento de Independencia. Miguel Hidalgo se presenta al centro, arengando a los pueblerinos con el estandarte de la Virgen de Guadalupe en una mano y también el puño al aire, como imagen espejo con la escena de la izquierda. Inclusive todos los personajes tienen el puño levantado, en alusión a la rebelión. También se observa un pergamino frente a la muchedumbre, superpuesto y con la frase Abolición de Esclavitud escrita en él, y unas cadenas rotas. Este último simbolismo también es usado con frecuencia en el arte, representando la liberación de las personas oprimidas (ver imagen 9). 


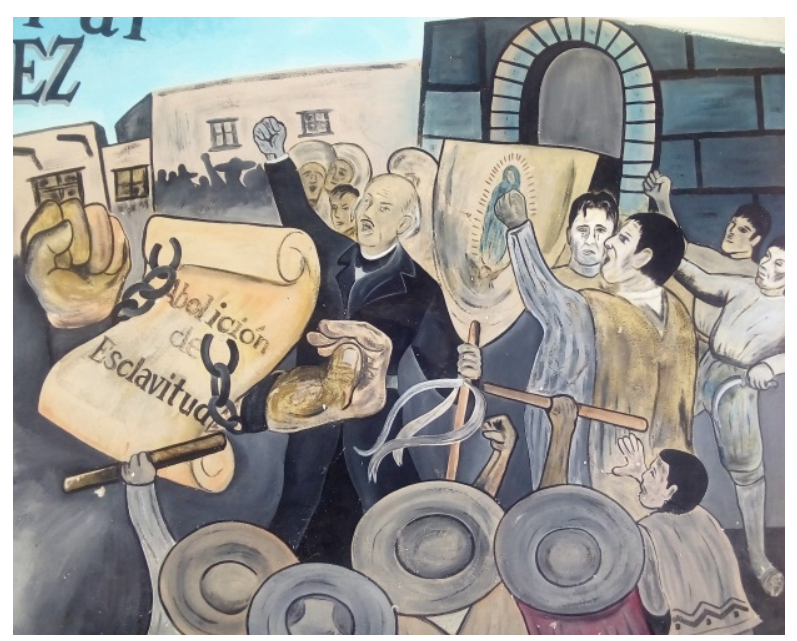

Imagen 9. Mural 2. Detalle de la escena 2. Fotografía: Adán Erubiel Liddiard.

Tanto la figura central como las escenas de los lados están acogidas en un fondo completamente azul, el de un cielo sin nubes que lo cubran, ni contratiempos que frenen la lucha independentista iniciada. Es de tomar en cuenta la combatividad reflejada en este mural. Es probablemente la combatividad que quiso ser transmitida hacia los niños como esencia de los héroes de Independencia.

Este mural representa cómo los valores que se le dan al héroe en busca de su mitificación, y en pos de un sentimiento nacionalista, se pueden ayudar del realce visual que brinda el arte plástico. Esto ofrece, dentro de las propiedades inherentes al muralismo, un enriquecimiento a la experiencia de sólo conocer el tema, volviéndola también sensorial.

Se entiende como abrir el trabajo histórico a la población en general por medio del trabajo artístico. Aprovechar todas las cualidades de impacto y ubicación que brinda el muralismo para acercar las ideas al público. Por último, representa tomar la cualidades de glorificación del personaje histórico, propias de la historia oficialista, y masificarlo vía 
los murales en los paredes de las instituciones públicas, tal y como lo hacía la ya mencionada escuela del Muralismo Mexicano, a mediados del siglo XX.

Esta corriente artística/política/social es reconocida por gestarse en diversos recintos públicos del centro y sur del país, seleccionados por su importancia en esa época. Los maestros muralistas mexicanos evocaban al pasado, y ayudaban a su vez a construir una imagen de país, de un México reconstruido (Sánchez-López, 2013).

A pesar de que el Muralismo Mexicano guarda algunos aspectos historicistas en su concepción, sobre todo la fundamentación de un sentimiento nacionalista como objetivo; el que su florecimiento se haya dado en el periodo histórico que abarca el paradigma idealista (Santana, 2005), hace que decante más por esta corriente generacional. Así, la forma de entender a la figura histórica se hace aún más idealizada y menos crítica. Aunado a esto, los muralistas mexicanos también importaban ideas de un socialismo que se asentaba cada vez más en la Europa de esos años. Por esto la lucha de clases se veía casi a cada pincelada, en cada puño levantado, y en cada martillo de obrero y hoz de campesino. Todas estas particularidades se fusionaron y dieron identidad propia al quehacer muralista en México.

En el mural escolar de primaria donde se apuesta por la figura histórica, se encuentra parte de lo anteriormente mencionado, sobre todo si la temática está centrada en la Revolución Mexicana, cuna del

144 pensamiento del Muralismo Mexicano, tanto pictóricamente como ideológicamente. Prueba de esto es el siguiente mural, localizado en la Escuela Primaria Revolución, ubicada en la calle Ma. Elena Hernández s/n, de la colonia Revolución (ver imagen Io). 


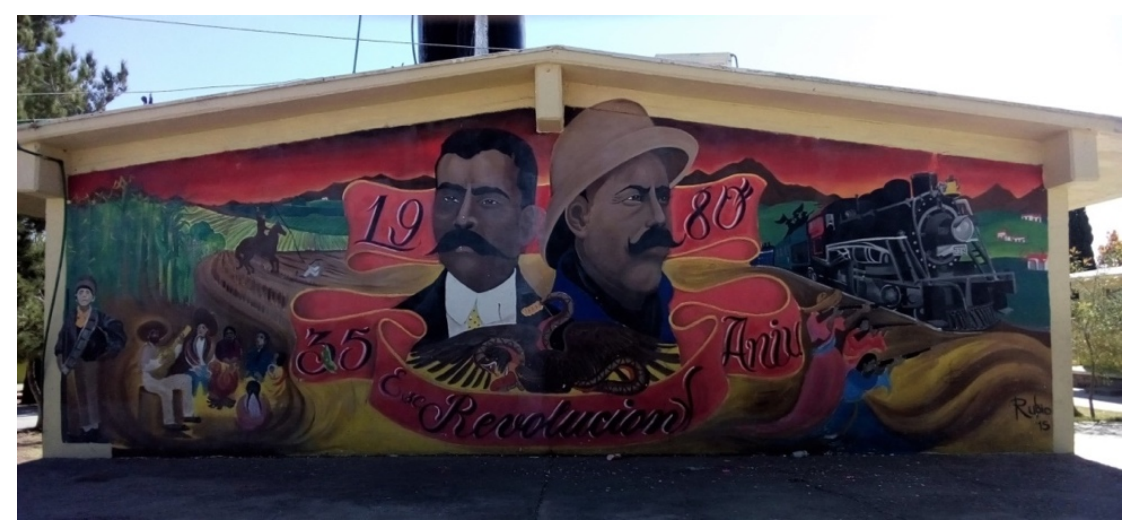

Imagen Io. Mural 3. 35to Aniversario de la Escuela Revolución. Autor: Jorge Rubio. Fotografía: Adán Erubiel Liddiard.

Lo primero que resalta en esta pintura es el cintillo que manifiesta que fue elaborado expresamente para el 35to aniversario de la escuela en cuestión, la cual fue fundada en $\mathbf{1 9 8 0}$, como se lee en un principio. Se corrobora el dato de la celebración con el año de elaboración, 20I5, inscrito junto a la firma del artista (ver imagen II).

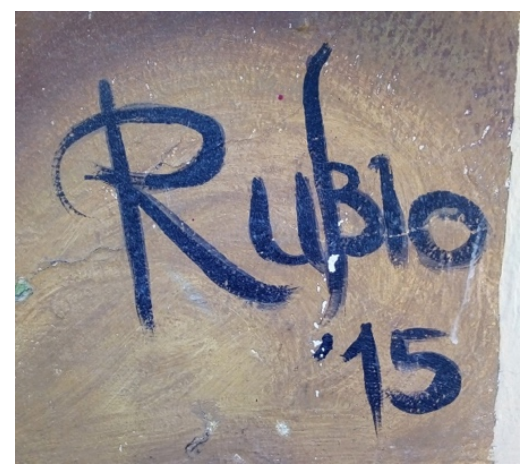

Imagen II. Mural 3. Detalle de la firma del autor. Fotografía: Adán Erubiel Liddiard. 
Dentro de la composición también destacan los rostros de gran tamaño de los personajes históricos, Emiliano Zapata y Francisco Villa, figuras representativas de la Revolución Mexicana. Ambos forman un tipo de ser bicéfalo que vigila con su doble mirada todos los ángulos de visión del espacio frente a ellos. Detrás de sus ceños fruncidos parecen develarse pensamientos para calcular nuevas estrategias para el campo de batalla. En medio de los dos se revuelven el águila devorando la serpiente, en cruenta pose. La alegoría se dirige hacia lo atroz que fue esta gesta militar, lo larga y lo dolorosa que fue. Y como la nación, encarnada en estos simbólicos animales, estaba en constante masacre fratricida, de mexicanos contra mexicanos. El constante color rojo del fondo lo refuerza (ver imagen I2).

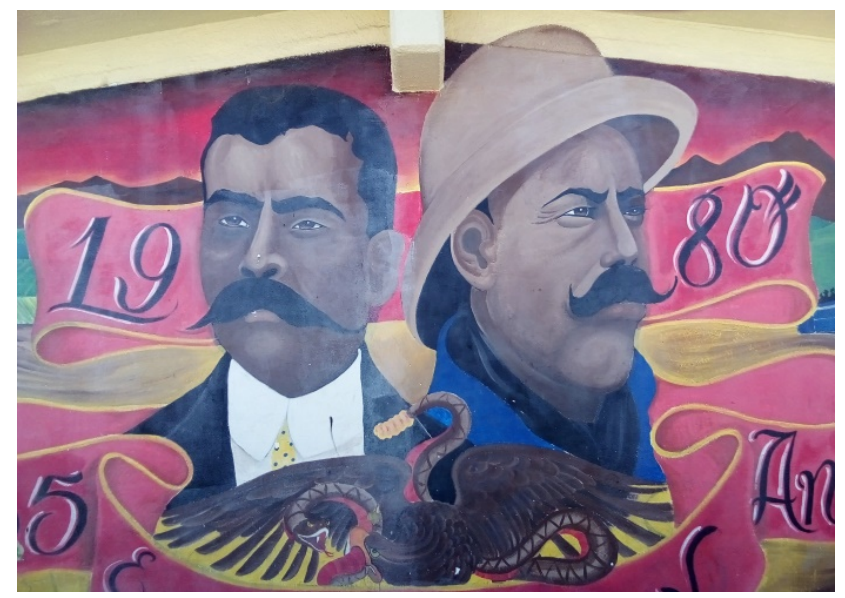

Imagen I2. Mural 3. Detalle de las figuras históricas. Fotografía: Adán Erubiel Liddiard.

Por tercera vez los personajes históricos seleccionados inciden en el nombre de la escuela, corroborando la relación. Y al igual que en el mural de Ortiz de Domínguez, se recrean múltiples y coloridas escenas 
narrativas, ahora revolucionarias, situadas a los lados de la estampa central. Se analizarán sólo un par por cuestión de espacio. La primera hace referencia a la desigualdad social y atropellos que se vivían en la época, con una representación cruda de un hacendado a caballo lacerando con un látigo a un campesino ya sometido y tirado en las líneas de arado (ver imagen $\mathrm{I3}$ ).

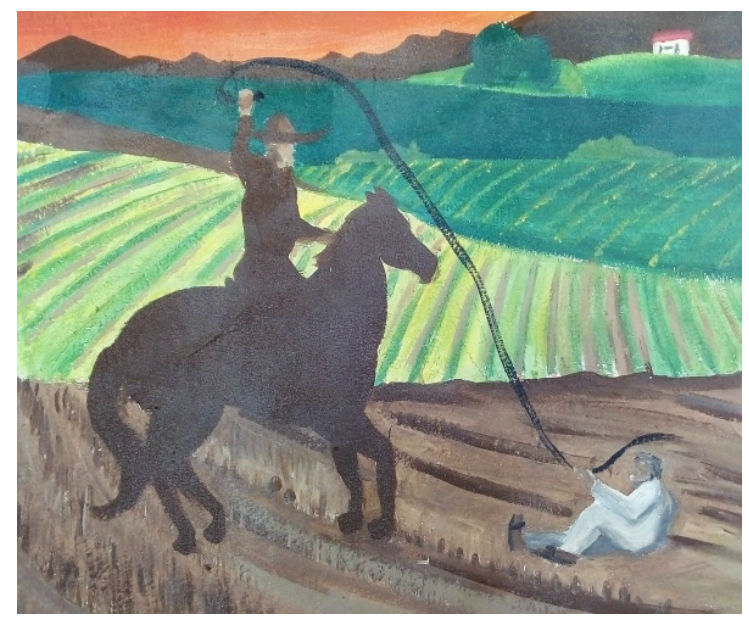

Imagen I3. Mural 3. Detalle de la escena I. Fotografía: Adán Erubiel Liddiard.

Aunque esta escena fue parte del México rural porfirista, en donde se gesta el descontento que llevó a las armas a las clases más humildes, es también un ejemplo de cómo representaciones artísticos de situaciones reales, son usadas para validar acciones y hechos históricos. Hay que recordar que el muralismo es utilizado en ocasiones para dramatizar los fragmentos del pasado que el grupo en el poder necesita resaltar.

La siguiente escena es menos severa y más amable. Contiene personas de la época en sus actividades diarias, en este caso calentándose alrededor de una fogata, probablemente después de alguna faena de 
campo o al terminar una batalla. Uno de los personajes anónimos ameniza la velada tocando su guitarra. La representación de esta particular situación lleva a la memoria a la manera como se compusieron los corridos revolucionarios (ver imagen I4). Estos son la vía por la que se conocen hoy muchos hechos de la época, inclusive algunos estudiados en las aulas de la escuela referida.

Se aprecia también otro personaje en primer plano, apenas un niño, y erguido con orgullo. Es homenaje a las fotografías de los infantes que se enlistaron valerosos a las filas revolucionarias. Aunque, al igual que la escena del hacendado golpeando el campesino, podría percibirse como una representación idealizada de los hechos, sobre todo conociendo el inhumano proceso de reclutamiento forzoso que representaba la leva.

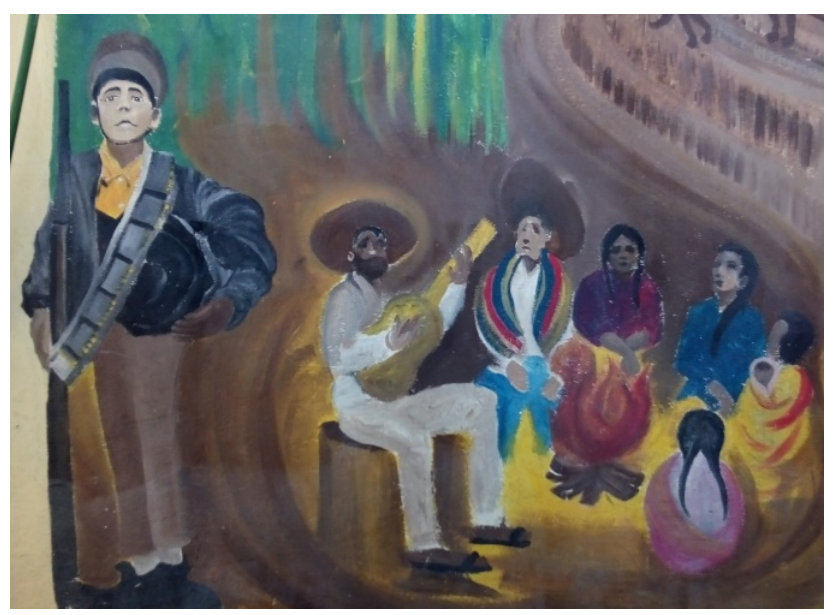

Imagen I4. Mural 3. Detalle de la escena 2. Fotografía: Adán Erubiel Liddiard.

Recapitulando, las escenas integradas en este mural son pasajes cotidianos y habituales, pintorescos y llenos del folklor del México rural de principios del siglo $\mathrm{XX}$, destacables desde el comienzo del 
muralismo moderno en el país (Sánchez-López, 2013). Y ya en conjunto con las escenas del segundo mural, son piezas que abonan hacia ese potencial aprendizaje de historia nacional que se quiere proporcionar, en el seno de la institución educativa que decidió pintar una obra de este talante.

Ahora, se ha mencionado ya bastante del querer educar a los alumnos de primaria con los murales que se pintan en sus escuelas. Esto trae el carácter educativo del muralismo a la mesa de análisis, pudiéndose empezar a reflexionar desde la sapiencia de que este carácter educativo deviene también de la influencia de la escuela muralista mexicana de la postrevolución. Sobre todo de la visión de José Vasconcelos, primer secretario de educación pública del país, artífice de la difusión cultural nacional, y llamado el apóstol de la educación.

Sánchez-López (2013) concatena el llamado de Vasconcelos hacia la educación de la nación con el fenómeno muralista, mencionando que "la acción vasconcelista es fundamental para iniciar y consolidar este amplio y diversificado proyecto el cual, al estar orientado en gran medida a una población analfabeta, buscaba generar en las imágenes un medio didáctico al que todos podían acceder" (p. 69).

El proyecto vasconcelista en México buscaba ofrecer educación a la gran mayoría iletrada del país, moldeando de paso su sentimiento patriótico a través de las imágenes en las paredes de aquellos edificios estratégicamente elegidos; el mural con figura histórica de las primarias en Chihuahua se puede visualizar como una extensión del libro de texto. Así se fundamenta plenamente el carácter educativo del muralismo de este tipo, al transformarse en un refuerzo de las lecciones de las clases de historia. Un refuerzo que está ahí, a diario, enfrente de su público cautivo. 
En resumen, los murales de características historicistas intentan explicar el pasado con sus escenas simbólicas y poetizadas, y la figura histórica es importante para llegar más rápidamente a la apelación emocional. No hay nada mejor que los héroes y los villanos para crear historias. Aunque como se sabe, el pasado siempre se explica con la óptica del vencedor, o con el sesgo político del momento actual. A veces con el paso del tiempo los héroes se convierten en villanos y viceversa, y los murales son destruidos y vueltos a pintar, adecuándose al paradigma imperante.

\section{Mural oficial en las escuelas}

Dentro de todos los detalles detectados en el trabajo muralista de las escuelas primarias, hay uno en particular, el referente a que los cuidados y resguardo que se dan a un mural pintado por alumnos o maestros, relacionado a la mera decoración, o como actividad escolar o extra curricular, son menores a los que se les brindan al mural que tienen una figura histórica en su temática y concepción.

Este segundo tipo de mural conlleva mayor valoración por propios y extraños, ya que se relaciona con la seriedad buscada en una institución educativa. Inclusive llega a ser considerado el único al que se le puede llegar a llamar un verdadero mural. Esto porque se acerca más, como se expuso anteriormente, a la experiencia visual de las obras de los maestros muralistas de la postrevolución. Existe entonces, una dualidad de percepción entre los murales con temática y presentación historicista, y los que contienen elementos más casuales.

En una publicación anterior relacionada, se ha expuesto que este fenómeno es recurrente en el muralismo de la ciudad (Liddiard y Hernández, 2019). Ahí se analiza cómo existen murales que son 
concebidos dentro de la solemnidad, siendo solicitados por canales institucionales y develados con el debido protocolo y rituales que la autoridad escolar marca. Estos son cuidados y restaurados, dándoles un estatus importancia en su espacio.

En contraparte, también se abordan los que subsisten dentro de la invisibilidad, la irrelevancia y la temporalidad. Invisibilidad al estar en espacios no tan preferentes, en zonas poco frecuentadas. Irrelevancia por generar poca expectación y menosprecio al observarse. Y temporalidad cuando la característica efímera del mural se acentúa por el poco cuidado. Se llega entonces a la conclusión de que existe el mural oficial y el no oficial, con las particulares descritas (Liddiard y Hernández, 2019).

La escuela primaria no es ajena a esta dualidad muralista, y las obras presentadas en este trabajo son ejemplos de la tendencia hacia la institucionalidad que puede llegar a tener el mural escolar. Más aún coronado con la validez y realce que la figura histórica brinda. Al final son muestra de cómo el respeto que inspira el personaje puede trasladarse a un muro, generando una cultura instantánea de cuidado, tanto por parte de las autoridades como de los mismos alumnos. Es una cadena visible de continuidad hacia los murales oficiales en Chihuahua, en donde:

Se les protege del daño accidental de los paseantes, de la crudeza del clima de la región, y de los diversos percances que pudieran presentarse. Hasta se invierte en su restauración en caso de ser necesario, para que el trabajo pictórico dure el mayor tiempo en la mejor condición posible (Liddiard y Hernández, 20I9, p. 898).

A continuación y para concluir la reflexión del muralismo oficial, se presentan los murales de Emiliano Zapata y de Sor Juana Inés de la 
Cruz, ambos dentro de la Escuela Primaria Emiliano Zapata, ubicada en la calle Francisco I. Madero \#IOI, de la colonia Villa Juárez (ver imágenes I5 y I6).

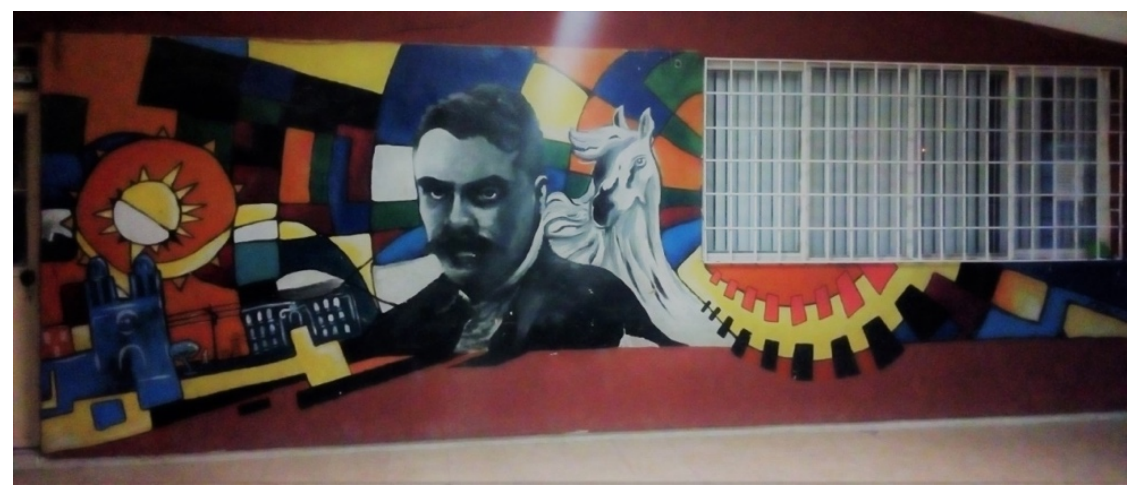

Imagen I5. Mural 4. Emiliano Zapata. Autores: Colectivo Los Mismos. Fotografía: Adán Erubiel Liddiard.

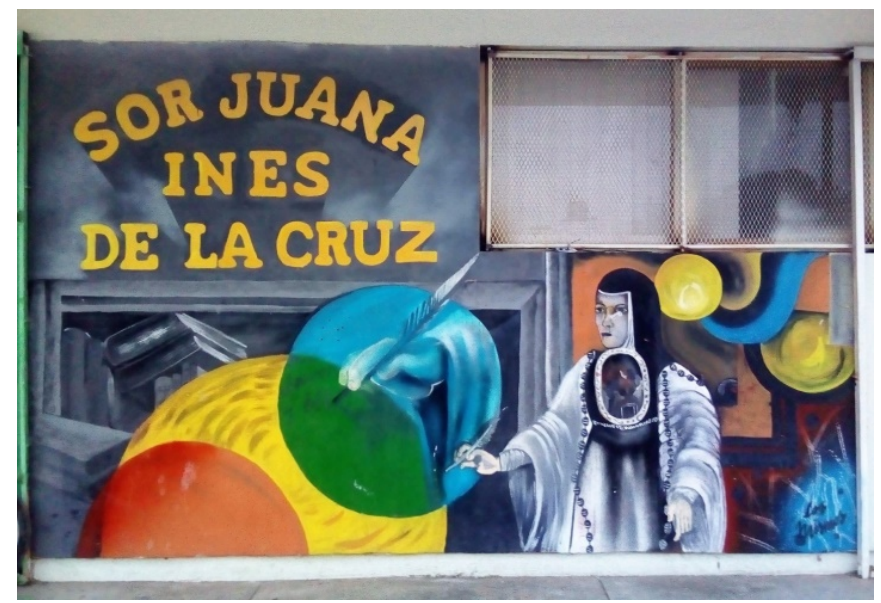

Imagen I6. Mural 5. Sor Juana Inés de la Cruz. Autor: Colectivo Los Mismos. Fotografía: Adán Erubiel Liddiard. 
Estos presentan la particularidad de estar contenidos en la misma institución, a pesar de representar cada uno diferente figura histórica, y es porque uno es representativo del turno matutino y el otro del el turno vespertino. Físicamente, el de Emiliano Zapata se encuentra en el pórtico justo pasando la entrada principal, y el de Sor Juana Inés de la Cruz está enfrente del patio principal, en la pared de las aulas. Ambos fueron pintados en el 2012.

Se puede apreciar que la estética de estas pinturas es distinta a la de las anteriormente presentadas. Mientras que en aquellas la solemnidad y el discurso visual de estampa escolar era innegable, en estas se distingue un concepto distinto en los elementos que rodean las efigies de los personajes. Es libre, artístico y fluido en todas direcciones. Se contempla geométrico y orgánico por las diversas figuras circulares usadas. Incluso onírico por como resalta la mano, pero deja en la figura humana ese pequeño remanso de respeto a lo clásico. Este giro creativo, avalado por los directivos en turno, se presenta ya que el autor es miembro de un colectivo llamado Los Mismos, con obras murales del tipo urbano a lo largo de la ciudad de Chihuahua, caracterizadas, además por su alta calidad técnica, por su frescura en cuanto a propuesta (ver imagen $\mathrm{I} 7$ ).

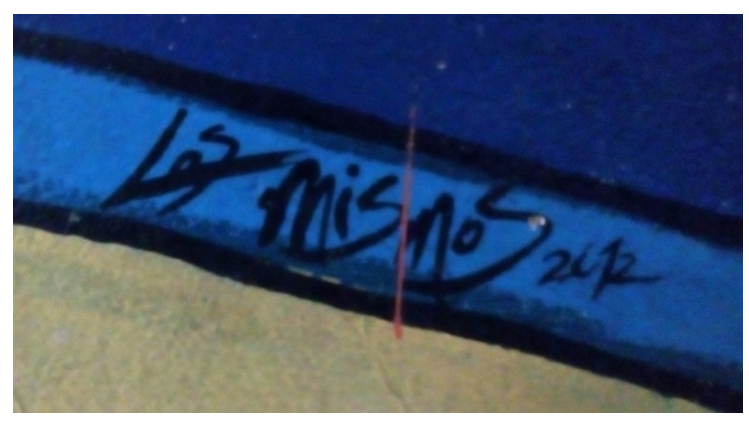

Imagen 17. Mural 4. Detalle de la firma de los autores. Fotografía: Adán Erubiel Liddiard. 
Entonces, se aprecia tanto al viril caudillo revolucionario, como a la atormentada pero valiente poetisa colonial, conviviendo con novedosos objetos y fondos, no muy comunes a su imaginario conocido. Los dos, cada uno en su pared, parecen atrapados en una telaraña multicolor. Pero el artista los acompañó de otros detalles, que ya no resultan tan extraños, como el fiel caballo blanco, compañero de mil batallas (ver imagen I8), o la pluma sobre la hoja, llena de tinta e inspiración (ver imagen 19).

En ambos murales se termina exhibiendo los rostros como se entienden, tan familiares para la memoria colectiva como se puedan pintar. Así estas obras de estilo poco común se transmutan, para volverse parte de la institución. Y como cualquier otro objeto simbólico, respetado y cuidado, adquieren el carácter de oficiales, de murales oficiales.

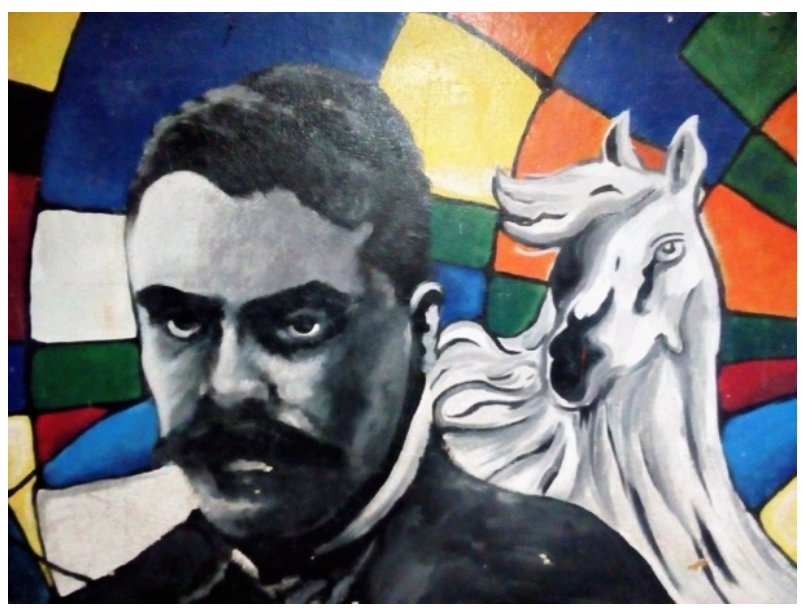

Imagen I8. Mural 4. Detalle de la figura histórica. Fotografía: Adán Erubiel Liddiard. 


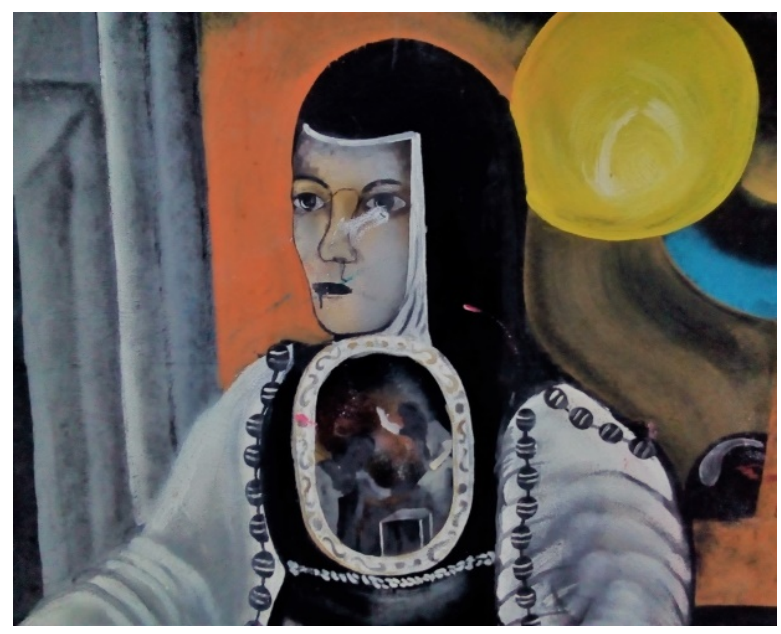

Imagen 19. Mural 5. Detalle de la figura histórica. Fotografía: Adán Erubiel Liddiard.

\section{Conclusiones}

Se ha expuesto que los murales escolares de características historicistas conllevan de forma inherente propósitos educativos. Es relevante introducir una primera conclusión: estas obras confieren al muro seleccionado para su ubicación un carácter distinto al de los demás. Esta pared se convierte instantáneamente en un punto referencial dentro de la escuela, y resalta de las demás edificaciones alrededor.

Otra conclusión asociada a la anterior se aborda al subrayar que el mural llega a tener una función recurrente en las escuelas: representar a la institución. En la investigación de campo fue frecuente advertir como las comunidades estudiantil, académica y administrativa, crean un vínculo con los objetos que conlleven una liga emocional con el recinto en el que pasan gran parte del día. Pueden ser en forma de 
playeras, tazas, o cualquier utensilio que tenga un distintivo visual que los diferencie de las otras instituciones educativas.

Entonces, estos objetos se convierten en fetiches a los que se les confiere, no un poder mágico, pero sí simbólico (Hernández, Pérez y Trujillo, 20I8), el de promover la sensación de unidad. El mural escolar pertenece a esta categoría de fetiches, y potencia el orgullo si en él se distingue la figura histórica que presta su nombre a la institución. En pocas palabras, ofrece sentido de identidad. Este, en la cotidianeidad de las actividades diarias, es el que hace que se desee pertenecer a un grupo y que se quieran hacer mejor las tareas encomendadas. Se encuentra en el llegar a la jornada de estudio o trabajo, y sentirse relacionado con las demás personas alrededor, y en lo posible ayudarlas a mejorar. Es crisol de ánimos para crear una sinergia de prosperidad.

Es por esto que los directivos de las escuelas primarias se toman el tiempo y esfuerzo de procurar un mural representativo, ya que frecuentemente se convierte un espacio para la unidad del alumnado, aunque los mismos escolares a veces no se den cuenta de esto. Siempre es plausible cualquier esfuerzo para generar una carga emotiva de bien para los niños, y es como se aprecia al final el mural escolar con figura histórica, más allá de su función educativa o hasta doctrinaria.

\section{Referencias}

156 Gombrich, E. H. J. (2003). Los usos de las imágenes. Estudios sobre la función social del arte y la comunicación visual. Distrito Federal, México: Fondo de Cultura Económica.

Hernández, G., Pérez, F. A., y Trujillo, J. A. (20I8). Mitos, ritos, utopías, idolatrías, alienación y fetiches de la educación. Debates por la Historia, 6(I), I93-2I2. Recuperado de 
https://vocero.uach.mx/index.php/debates-por-lahistoria/article/view/13/24

Jung, C. G. (1995). El hombre y sus símbolos. Barcelona, España: Paidós Ibérica.

Liddiard, A. E., y Hernández, G. (2019). El otro muralismo en la ciudad de Chihuahua. RECIE. Revista Electrónica Científica de Investigación Educativa, 4(2), 897-907. Recuperado de http://www.rediech.org/ojs/20I//index.php/recie/article/view/32 2/453

Read, H. (1954). El significado del arte. Buenos Aires, Argentina: Editorial Losada.

Sánchez-López, I. (2013). Representaciones y expresiones de lo mexicano en los muralistas de la primera generación. Contribuciones desde Coatepec, (24), 67-83. Recuperado de https://www.redalyc.org/pdf/28I/28I26456009.pdf

Santana, J. M. (2005). Paradigmas historiográficos contemporáneos. Barquisimeto, Venezuela: Fundación Buría.

Sierra, M. de las M. (2016). El muralismo y la imagen en movimiento; construcción de nuevas narrativas. Reflexiones del Muralismo en el Siglo XXI, (2), 50-66. Recuperado de http://www.muralismounam.com/assets/revistareflexionesno2.pdf

Este artículo se publica bajo una licencia de Creative Commons Reconocimiento-NoComercial 4.0 Internacional, y puede ser usados gratuitamente para fines no comerciales, dando los créditos a los autores y a la revista. 